Nig. J. Biotech. Vol. 37(1): 122-128 (June 2020)

ISSN: 01891731

Available online at

http://www.ajol.info/index.php/njb/index

and www.biotechsocietynigeria.org

DOI: https://dx.doi.org/10.4314/njb.v37i1.13

\title{
Enterobacterial Repetitive Intergenic Consensus (ERIC) as a tool for genetic characterisation of bacterial isolates in Nigeria
}

\author{
${ }^{1 *}$ Otokunefor, K., ${ }^{1}$ Ogugbue, C. J. and ${ }^{2}$ Fajoyomi, B. U. \\ ${ }^{1}$ Department of Microbiology, Faculty of Science, University of Port Harcourt. \\ ${ }^{2}$ Department of Microbiology Technology, School of Science Laboratory Technology, University of Port \\ Harcourt.
}

\begin{abstract}
Genetic characterisation as a tool for identification of bacterial isolates in Nigeria has been on the increase in recent years, and the 16s rRNA typing has been a preferred method. Due to cost limitations, there is a need to explore other genetic options. Enterobacterial Repetitive Intergenic Consensus (ERIC) polymerase chain reaction (PCR) analysis is a PCR- only based system which offers the advantage of reduced cost. This study set out to explore the use of ERIC-PCR in genetic characterisation of some selected bacterial isolates from Nigeria and compare it with genetic characterisation using 16s rRNA sequence typing. ERIC-PCR and 16s rRNA typing were carried out on 15 isolates following previously described protocols. Using 16s rRNA typing, thirteen different bacterial species were identified of which majority $(85.7 \%)$ were Gram negative, with $57.1 \%$ belonging to the Enterobacteriaceae family. Using ERIC-PCR, only 13 of the 15 isolates $(86.7 \%)$ could be typed, resulting in the identification of the 13 different types. ERIC-PCR was able to accurately differentiate between two members of the Proteus species, as well as identify the organisms as similar based on the banding pattern. The results show that ERIC-PCR may play a role as a bacterial identification tool but this role might be more suited to differentiating closely related members of a genus or typing within species rather than general bacterial identification.
\end{abstract}

Keywords: Genetic characterisation, 16s rRNA, ERIC-PCR, Nigeria

*Corresponding Author: kome.otokunefor@uniport.edu.ng +234-8051844470

\section{Introduction}

The use of $16 \mathrm{~s}$ ribosomal RNA (16s rRNA) sequencing in the identification of bacterial isolates in Nigeria has been on the increase in recent years as observed by a Google scholar search for $16 \mathrm{~s}$ Nigeria which noted 6840 articles between 2015 and 2019 and, 3320 between 2010 and 2014 (Google Scholar search, $3^{\text {rd }}$ March 2020). This phenomenon is probably due to the limitations associated with phenotypic characterisation. The use of $16 \mathrm{~s}$ involves the amplification, sequencing and sequence analysis of a $1500 \mathrm{bp}$ fragment of the bacteria 16s rRNA gene (Clarridge 2004). This method has found wide application in bacterial identification due to its ease and specificity (Xia et al., 2015). One major limitation of this technique in comparison with phenotypic and non sequence based molecular typing techniques, however, is its high cost (Souza et al., 2010). This has led to most studies only characterising a subset of the isolates. The cost of characterisation by 16 s sequencing is driven by the sequencing step in the technique rather than the polymerase chain reaction (PCR) amplification of the $16 \mathrm{~s}$ gene fragment.

Enterobacterial Repetitive Intergenic Consensus (ERIC) sequences are repetitive imperfect palindromes, 127 bp in size which 
occur in multiple copies on bacterial genomes. ERIC-PCR analysis is a PCR- only based genotyping system which involves amplification of the region between the ERIC sequences and differentiates bacterial strains based on variations in location of ERIC sequences present i $\mathrm{n}$ the bacteria genome (Wilson and Sharp, 2006). Though initially described in members of the Enterobacteriaceae family, these sequences have in more recent years been described in a wide variety of bacteria and variations in their location has served as the basis of strain typing (Haitao et al., 2011; Wuturangi et al., 2012; Dorneles et al., 2014).

Considering the increased detection of ERIC sequences in more bacterial species, this study set out to explore the use of ERIC-PCR in genetic characterisation of selected bacterial isolates from Nigeria and compare it with genetic characterisation using 16s rRNA sequencing.

\section{Materials and Methods}

\section{Study Isolates}

Fifteen (15) bacterial isolates were randomly selected from the poultry isolates collection of the research group at the Department of Microbiology, University of Port Harcourt.

\section{Molecular Characterisation of the Isolates 16s rRNA sequence typing}

Extraction of genomic material was carried out on a 24 hour subculture using the ZR fungal/bacterial DNA miniprep kit (ZymoResearch, California, CA USA) according to manufacturers' instructions. Amplification of the 16s rRNA gene fragments was carried out following standard protocol in an ABI 9700 GeneAmp PCR System (PE Applied Biosystems, Norwalk, CT, USA) using the 16s 27F (5'AGAGTTTGATCCTGGCTCAG3') and 1492R
(5'GGTTACCTTGTTACGACTT 3') universal primers which generate a 1500 bp DNA fragment (Chikere and Ekwuabu, 2014). In brief, amplification was carried out in a $50 \mu \mathrm{l}$ reaction volume containing 2.5 units of Dream Taq master mix (Taq polymerase DNTPs, $\left.\mathrm{MgCl}_{2}\right), 0.4 \mathrm{M}$ of the primers and $2 \mu \mathrm{l}$ of the template DNA (template). Amplification protocol consisted of a 5 min initial denaturation at $95^{\circ} \mathrm{C}$, followed by 30 cycles of denaturation at $95^{\circ} \mathrm{C}$ for $30 \mathrm{~s}$, annealing at $52^{\circ} \mathrm{C}$ for $40 \mathrm{~s}$ and extension at $72^{\circ} \mathrm{C}$ for $50 \mathrm{~s}$, followed by a final extension at $72^{\circ} \mathrm{C}$ for 3 mins.

The amplicons generated were visualised on a $1 \%$ agarose gel and sequencing of purified amplified products was carried out using a 3500 genetic analyser. Sequences were then analysed to determine evolutionary history and determine isolate identity using the National Center for Biotechnology Information (NCBI) Basic Local Alignment Search Tool (BLAST) algorithm.

\section{ERIC-PCR typing}

ERIC-PCR typing first involved amplification of the genomic DNA using the ERIC primers ( $5^{\prime}$

-ATGTAAGCTCCTGGGGATTCAC-3') forward primer, (5' - AAGTAAGTGACTGGGGTGAGCG$3^{\prime}$ ) reverse primer as previously described (Xia et al., 2012). Following amplification, the banding pattern was analysed on a $1 \%$ agarose gel and isolate relatedness determined based on the banding pattern.

\section{Results}

16s rRNA typing

Following amplification of the 16s rRNA gene fragment, an analysis of the amplified products on agarose gel revealed that the amplification took place in all the isolates to generate 1500 bp amplicons (Figure 1).

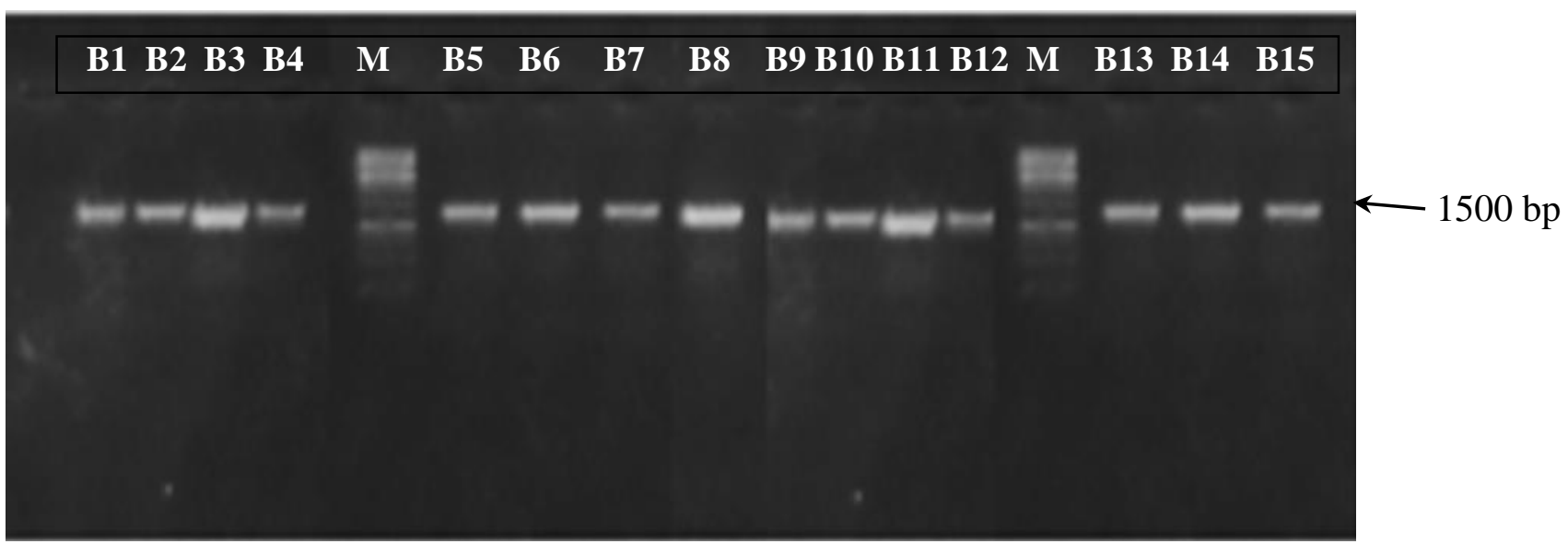

Figure 1: Product visualisation following 16s rRNA amplification 
Sequence analysis of the amplicons showed a high level of similarity between the test sequences and the sequences at the GenBank. The test isolates were found to belong to a wide range of bacterial families
(Figure 2). Majority (85.7\%) of these organisms were Gram negative, with the Enterobacteriaceae family being the most predominant family $(57.1 \%)$ represented (Table 1).

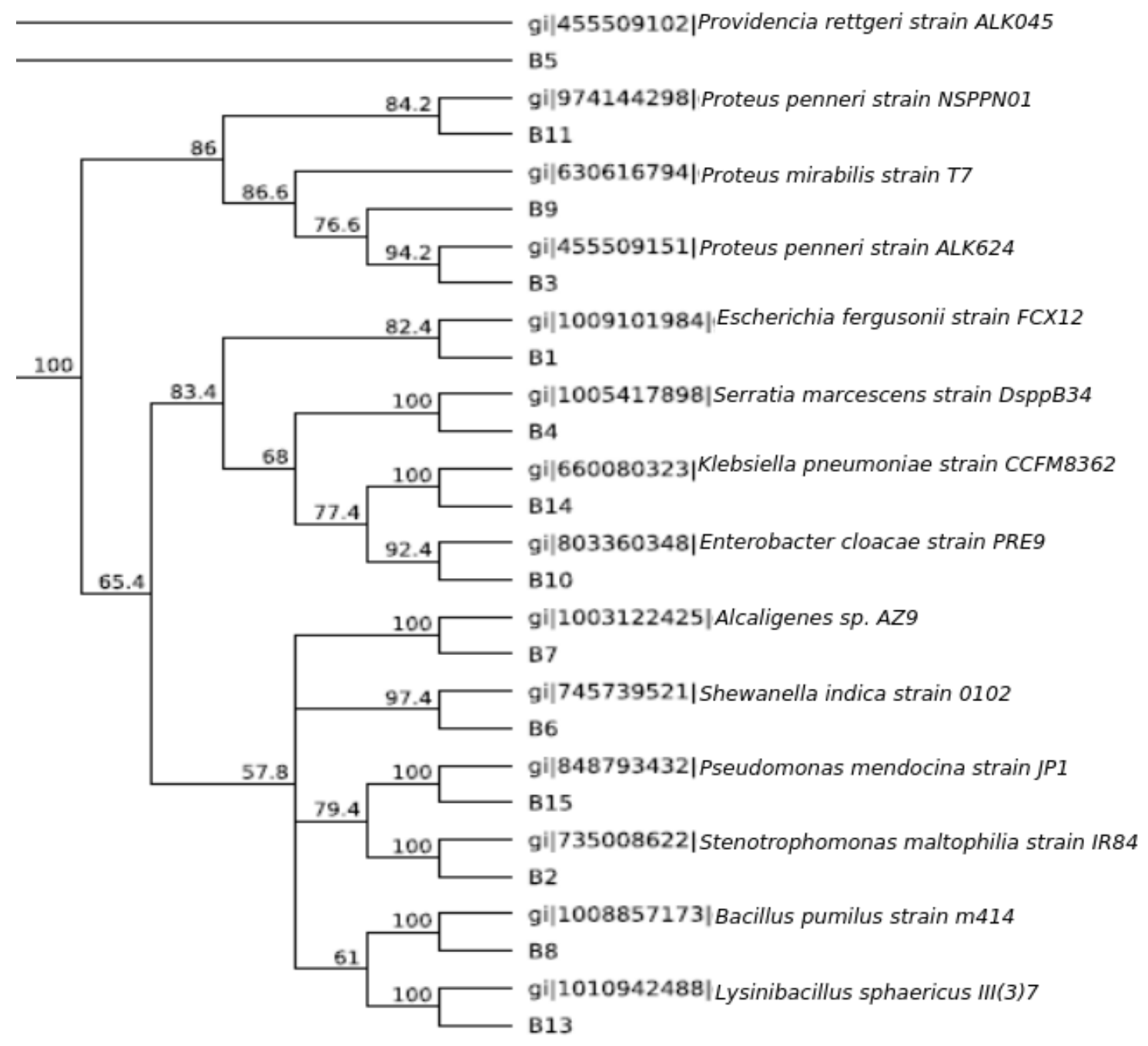

Figure 2: Dendrogram of bacteria identified using 16s rRNA sequence alignment.

Table 1: Gram identity and bacterial families of the test isolates

\begin{tabular}{clll}
\hline Isolate ID & Bacterial Identity & Gram Identity & Family \\
\hline B1 & Escherichia fergusonii & Gram negative & Enterobacteriaceae \\
& & & \\
B2 & Stenotrophomonas maltophilia & Gram negative & Non- Enterobacteriaceae \\
B3 & Proteus penneri & Gram negative & Enterobacteriaceae \\
B4 & Serratia marcescens & Gram negative & Enterobacteriaceae \\
B5 & Providencia rettgeri & Gram negative & Enterobacteriaceae \\
B6 & Shewanella indica & Gram negative & Non- Enterobacteriaceae \\
B7 & Alcaligenes sp & Gram negative & Non- Enterobacteriaceae \\
B8 & Bacillus pumilus & Gram positive & Non- Enterobacteriaceae \\
B9 & Proteus mirabilis & Gram negative & Enterobacteriaceae \\
B10 & Enterobacter cloacae & Gram negative & Enterobacteriaceae \\
B11 & Proteus penneri & Gram negative & Enterobacteriaceae \\
\hline
\end{tabular}




\begin{tabular}{llll}
\hline B12 & No Data & No data & No data \\
B13 & Lysinibacillus sphaericus & Gram positive & Non- Enterobacteriaceae \\
B14 & Klebsiella pneumoniae & Gram negative & Enterobacteriaceae \\
B15 & Pseudomonas mendocina & Gram negative & Non- Enterobacteriaceae \\
\hline
\end{tabular}

Following ERIC-PCR typing, bands were obtained in $86.7 \%(13 / 15)$ of cases (Figure 3). No bands were observed from two isolates namely Enterobacter cloacae and Alcaligenes sp. A total of 13 different banding patterns were observed. A binary code (Table 2) was created for each isolate using a scoring template of 1 for the presence of a band and 0 for the absence of a band (Arruda et al., 2003), with each band position serving as a locus.

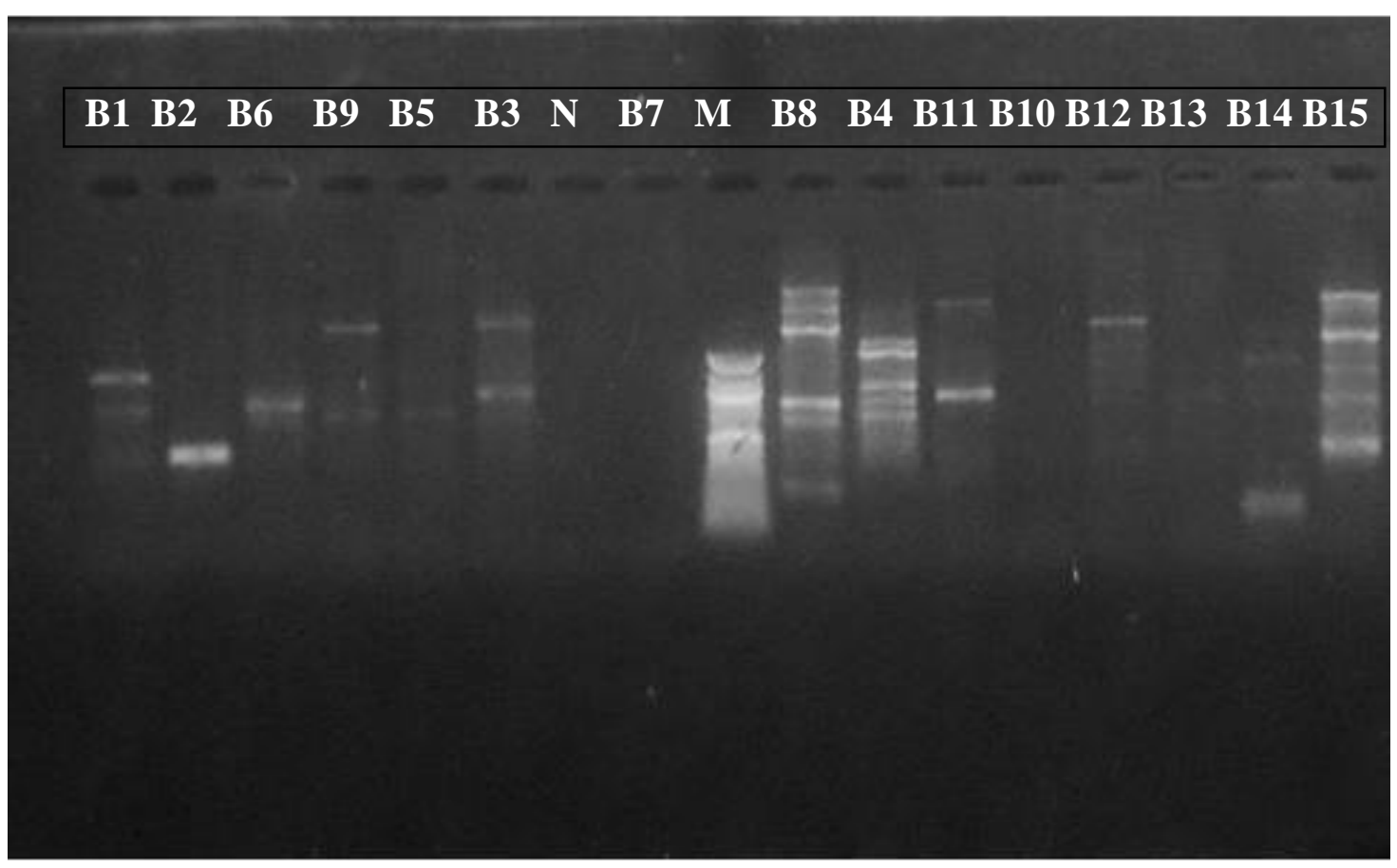

Figure 3: ERIC-PCR fingerprints of test bacterial isolates. $\mathrm{N}=$ Negative control, $\mathrm{M}=$ Molecular size markers

Table 2: Binary code interpretation of ERIC-PCR fingerprint

\begin{tabular}{|c|c|c|c|c|c|c|c|c|c|c|}
\hline \multirow{2}{*}{$\begin{array}{l}\text { Isolate } \\
\text { ID }\end{array}$} & \multicolumn{10}{|c|}{ Locus No } \\
\hline & 1 & 2 & 3 & 4 & 5 & 6 & 7 & 8 & 9 & 10 \\
\hline $\mathrm{B} 1$ & 0 & 0 & 0 & 0 & 0 & 1 & 0 & 1 & 1 & 0 \\
\hline B2 & 0 & 0 & 0 & 0 & 0 & 0 & 0 & 0 & 1 & 0 \\
\hline B6 & 0 & 0 & 0 & 0 & 0 & 0 & 1 & 1 & 0 & 0 \\
\hline B9 & 0 & 0 & 1 & 0 & 0 & 0 & 0 & 1 & 0 & 0 \\
\hline B5 & 0 & 0 & 0 & 0 & 0 & 0 & 0 & 1 & 0 & 0 \\
\hline B3 & 0 & 0 & 1 & 0 & 0 & 0 & 1 & 1 & 0 & 0 \\
\hline B8 & 1 & 1 & 0 & 1 & 0 & 0 & 1 & 1 & 0 & 1 \\
\hline B4 & 0 & 0 & 0 & 1 & 1 & 1 & 1 & 1 & 0 & 0 \\
\hline B11 & 0 & 1 & 0 & 0 & 0 & 0 & 1 & 0 & 0 & 0 \\
\hline B12 & 0 & 0 & 1 & 0 & 0 & 0 & 0 & 0 & 1 & 0 \\
\hline B13 & 0 & 0 & 0 & 0 & 0 & 0 & 1 & 0 & 1 & 0 \\
\hline B14 & 0 & 0 & 0 & 0 & 1 & 0 & 0 & 0 & 0 & 1 \\
\hline B15 & 1 & 1 & 0 & 1 & 0 & 1 & 1 & 0 & 1 & 0 \\
\hline
\end{tabular}

Based on the binary data, a Dendrogram (Figure 4) was developed using Jaccard's similarity coefficient data by the unweighted pair-group method using arithmetic means 
(UPGMA), using the DendroUPGMA server (http://genomes.urv.cat/UPGMA) (GarciaVallve et al., 1999). Taking out of consideration the ERIC-PCR negative samples, a total of 4 clusters were identified. Apart from the Bacillus pumilus isolate which was clustered with Gram negative organisms in $B$, two out of the three Gram positive organisms were clustered in D. Cluster $\mathrm{C}$ was the only poly-cluster containing only Gram negative organisms.

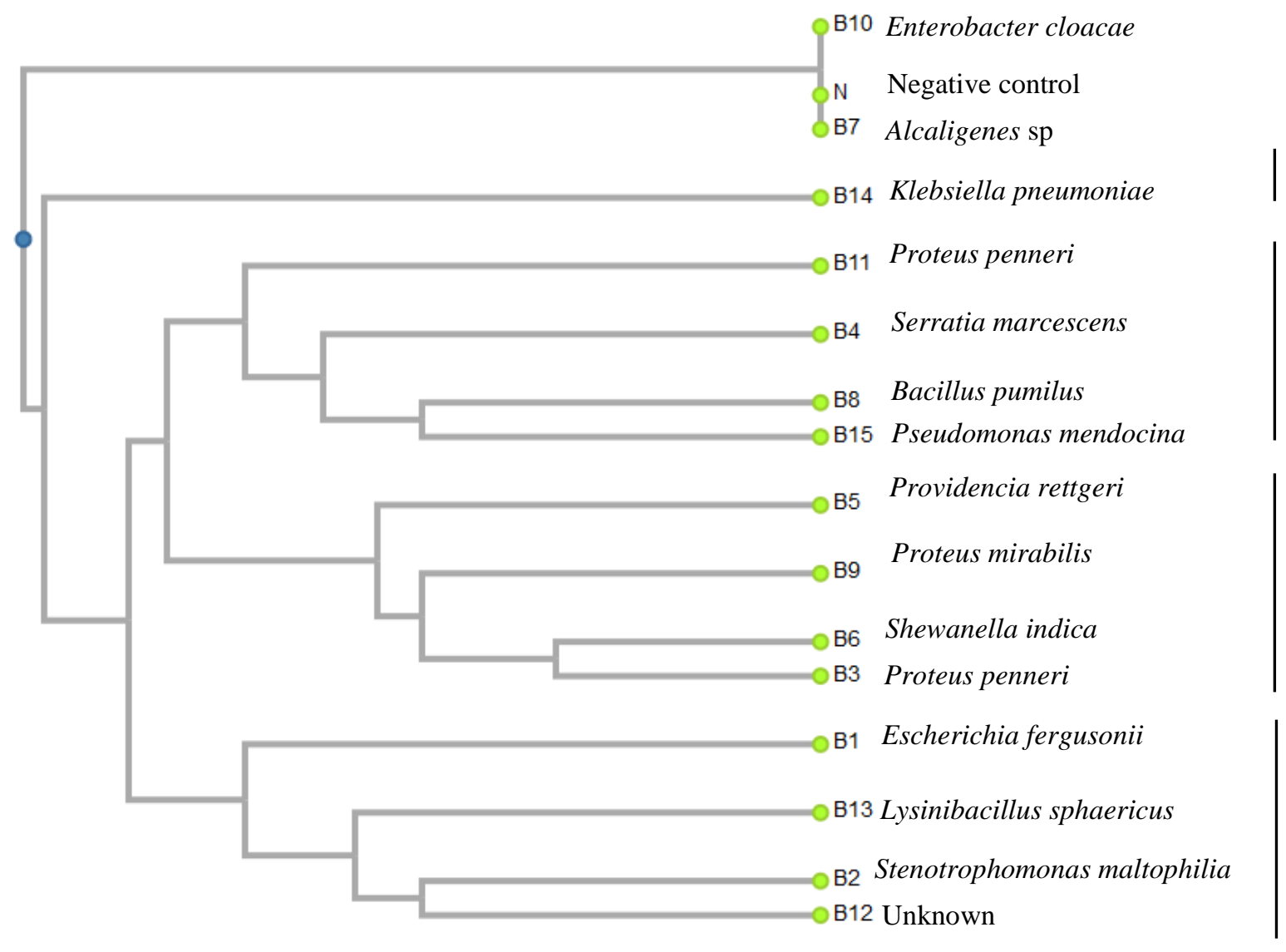

Figure 4: Dendrogram of the test isolates from UPGMA cluster analysis using Jaccard Similarity Coefficient of ERIC-PCR data

\section{Discussion}

Molecular identification of bacterial isolates is generally preferred to phenotypic typing methods as a result of higher levels of specificity and discrimination (Castro-Escarpulli et al., 2016). The use of 16s rRNA specifically for bacterial identification is now a commonplace practice and allows for accurate identification, even to species level (Clarridge 2004, Srinivasan et al., 2015). This same level of specificity was also noted in this study whereby the 15 isolates analysed were identified as 14 different species. The 16s rRNA typing was sensitive enough to differentiate two different species of Proteus (Proteus penneri and Proteus mirabilis), which would be difficult using basic phenotypic identification tools. A key reason for this sensitivity is due to the fact
\end{abstract}

that 16s rRNA typing is based on the comparison of the gene fragment sequences with numerous other sequences deposited in curated databases. This sequencing step however provides the major disadvantage of the technique - cost. The cost of 16s rRNA analysis for one isolate was approximately 44

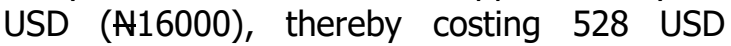
(A192000) for the 15 isolates. As previously reported, ERIC-PCR is a PCR- only based typing system and therefore has the advantage of cost (Foxman et al., 2005). With the current price of a pair of primers going for about 20 USD (A7000), and PCR amplification and product visualisation going for as low as 3 USD ( $\mathrm{A} 1000)$ in some cases, the total cost of ERICPCR analysis for 15 isolates comes simply to 60 USD (N22000). 
Though this technique has been used in genotyping, which differentiates strains of a specific species, its application as a tool for identification has been limited but suggested (Christiani et al., 2020). Whereas most studies focused on the ability of ERIC-PCR to discriminate between strains of the same or closely related species (Bakhshi et al., 2018; Aljindan et al., 2018; Kumar et al., 2019), this study clearly shows that ERIC-PCR is also able to discriminate between members of different species. Using ERIC-PCR, only 13 of the 15 isolates $(86.7 \%)$ could be typed, resulting in the generation of 13 different ERIC-PCR genotypes. Dendrogram analysis of the ERIC-PCR genotypes however failed to provide clear information on relatedness in some cases. With the 16s rRNA typing, a level of similarity was noted between both Gram positive Bacillus and Lysinibacillus but this was not observed using the ERIC-PCR typing. With respect to the three members of the Proteus sp present for which a level of similarity was noted using the 16s rRNA typing, ERIC-PCR was able to identify two as closely related. Additionally, an isolate belonging to the Providencia sp was also classed as similar to the Proteus isolates. As a genus, Providencia is closely related to Proteus and over the years several classifications and reclassifications were carried out before isolates were classed into the groups we work with now. For example, at one time, Providencia rettgeri, was classed as Proteus rettgeri (O'Hara et al., 2000). Classification of this cluster by both tests highlights the expected higher sensitivity and specificity of $16 \mathrm{~s}$ rRNA typing.

Results of this study therefore show that ERICPCR may play a role as a bacterial identification tool, providing more sensitive typing results than basic phenotypic typing methods. This role may however be a rather limited one and more suited to its traditional role in differentiating closely related members of a genus or typing within species rather than general bacterial identification.

\section{References}

Aljindan, R., Alsamman, K. and Elhadi, N. (2018). ERIC-PCR genotyping of Acinetobacter baumannii isolated from different clinical specimens. Saudi J. Med. Med. Sci. 6: 13.

Bakhshi, B., Afshari, N. and Fallah, F. (2018). Enterobacterial repetitive intergenic consensus (ERIC)-PCR analysis as a reliable evidence for suspected Shigella spp. outbreaks. Brazilian J. Microbiol. 49: 529 - 533.

Castro-Escarpulli, G., Alonso-Aguilar, N. M., Rivera, G., Bocanegra-Garcia, V., Guo, X., Juárez-Enríquez, S. R., . and Guadalupe, A. A. M. (2016). Identification and Typing Methods for the Study of Bac. Archives Clin. Microbiol. 7(1).

Chikere, C. B. and Ekwuabu, C. B. (2014). Molecular characterization of autochthonous hydrocarbon utilizing bacteria in oil-polluted sites at Bodo Community, Ogoni land, Niger Delta, Nigeria. Nig. J. Biotech. 27: 28 - 33.

Clarridge, J. E. (2004). Impact of $16 \mathrm{~S} r R N A$ gene sequence analysis for identification of bacteria on clinical microbiology and infectious diseases. Clin. Microbiol. Rev. 17: 840 - 862.

Cristiani, M., Flores, M. J., Brandi, R. J., Tedeschi, F. A., Zalazar, F. E. and Labas, M. D. (2020). ERIC-PCR technique applied to monitoring and quantification of DNA damage during water disinfection process. $\mathrm{J}$. Photochemistry Photobiology B: Biol. 202: 111699 .

De Arruda, M. C. C., Miller, R. N. G., Ferreira, M. A. S. V. and Felipe, M. S. S. (2003). Comparison of Crinipellis perniciosa isolates from Brazil by ERIC repetitive element sequence-based PCR genomic fingerprinting. Plant Pathol. 52: 236 - 244.

Dorneles, E. M., Santana, J. A., Ribeiro, D., Dorella, F. A., Guimaraes, A. S., Moawad, M. S., . and Gouveia, A. M. (2014). Evaluation of ERIC-PCR as genotyping method for Corynebacterium pseudotuberculosis isolates. PLoS One. 9: e98758.

Foxman, B., Zhang, L., Koopman, J. S., Manning, S. D. and Marrs, C. F. (2005). Choosing an appropriate bacterial typing technique for epidemiologic studies. Epidemiol. Perspect. Innov. 2: 10.

Garcia-Vallvé, S., Palau, J. and Romeu, A. (1999). Horizontal gene transfer in glycosyl hydrolases inferred from codon usage in Escherichia coli and Bacillus subtilis. Mol. Biol. Evolution. 16: 1125 - 1134.

Haitao, L. I., Dongming, L. I. U. and Jiguo, G. A. O. (2011). Differentiation between Bacillus 
thuringiensis and Bacillus cereus by $16 \mathrm{~S}$ rDNAPCR and ERIC-PCR. J. Northeast Agricul. Uni. (English Edition). 18: $12-15$.

Kumar, D., Sivakumar, S., Sharmila, P. and Sivasubramani, K. (2019). ERIC-PCR: A Molecular Typing Tool for Genotyping Multi Drug Resistant Pseudomonas aeruginosa Isolated from the Pus Samples. J. Drug Delivery Therapeut. 9: $1007-1011$.

O'Hara, C. M., Brenner, F. W. and Miller, J. M. (2000). Classification, identification, and clinical significance of Proteus, Providencia, and Morganella. Clin. Microbiol. Rev. 13: 534 - 546.

Souza, R. A., Pitondo-Silva, A., Falcão, D. P. and Falcão, J. P. (2010). Evaluation of four molecular typing methodologies as tools for determining taxonomy relations and for identifying species among Yersinia isolates. J. Microbiol. Methods. 82: $141-150$.

Srinivasan, R., Karaoz, U., Volegova, M., MacKichan, J., Kato-Maeda, M., Miller, S., . and Lynch, S.V. (2015). Use of $16 \mathrm{~S} r R N A$ gene for identification of a broad range of clinically relevant bacterial pathogens. PloS One. 10: e0117617.

Waturangi, D. E., Joanito, I., Yogi, Y. and Thomas, S. (2012). Use of REP-and ERIC-PCR to reveal genetic heterogeneity of Vibrio cholerae from edible ice in Jakarta, Indonesia. Gut Pathogens. 4: 2.

Wilson, L. A. and Sharp, P. M. (2006). Enterobacterial repetitive intergenic consensus (ERIC) sequences in Escherichia coli: Evolution and implications for ERIC-PCR. Mol. Biol. Evol. 23: 1156 - 1168.

Xia, L. P., Bian, L. Y., Xu, M., Liu, Y., Tang, A. L. and Ye, W. Q. (2015). 16S rRNA gene sequencing is a non-culture method of defining the specific bacterial etiology of ventilatorassociated pneumonia. Int. J. Clin. Experiment. Med. 8: 18560.

Xia, Y., Liang, Z., Su, X. and Xiong, Y. (2012). Characterization of carbapenemase genes in Enterobacteriaceae species exhibiting decreased susceptibility to carbapenems in a university hospital in Chongqing, China. Annals Lab. Med. 32: 270 - 275. 